\title{
Identification of Reverse Logistics Decision Types from Mathematical Models
}

\author{
Pascual Cortés PelliceriD, Faustino Alarcón Valero iD \\ Research Centre on Production Management end Engineering (CIGIP), Universitat Politècnica de València (Spain) \\ pascorpe@omp.upv.es,fanalva@omp.upv.es
}

Received: November 2017

Accepted: December 2017

\begin{abstract}
:
Purpose: The increase in social awareness, politics and environmental regulation, the scarcity of raw materials and the desired "green" image, are some of the reasons that lead companies to decide for implement processes of Reverse Logistics (RL). At the time when incorporate new RL processes as key business processes, new and important decisions need to be made. Identification and knowledge of these decisions, including the information available and the implications for the company or supply chain, will be fundamental for decision-makers to achieve the best results. In the present work, the main types of RL decisions are identified.

Design/methodology/approach: This paper is based on the analysis of mathematical models designed as tools to aid decision making in the field of RL. Once the types of interest work to be analyzed are defined, those studies that really deal about the object of study are searched and analyzed. The decision variables that are taken at work are identified and grouped according to the type of decision and, finally, are showed the main types of decisions used in mathematical models developed in the field of RL.

Findings: The principal conclusion of the research is that the most commonly addressed decisions with mathematical models in the field of RL are those related to the network's configuration, followed by tactical/operative decisions such as the selections of product's treatments to realize and the policy of returns or prices, among other decisions.

Originality/value: The identification of the main decisions types of the reverse logistics will allow the managers of these processes to know and understand them better, while offer an integrated vision of them, favoring the achievement of better results.
\end{abstract}

Keywords: reverse logistic, mathematical model, decision making, decision model

\section{Introduction}

Nowadays, the globalization, increased environmental regulation and pressure and demands of customer regarding environmental issues, have become a fundamental concern for companies (Aziziankohan, Jolai, Khalilzadeh, Soltani \& Tavakkoli-Moghaddam, 2017). Most of these companies, have integrated a sustainability focus into their business activities and strategies. In this regard, new reverse flows of products recovery are defined, with the firms' intention of reducing the environmental impact, improving the social presence and maximizing the economic value of products and production processes.

This new material flow, as opposed to the traditional or forward logistic flow, is known as reverse logistic flow or Reverse Logistics (RL) and includes, not only the transport of the product from the user to the producer or 
distributor, but also the classification and treatment of the recovered products and their different components. The management of the flows of return originated by diverse reasons and fomented by the different forms of reutilization and use, has received special attention since the beginning of the 21 st century (Pokharel \& Mutha, 2009).

During the last years, the rise of e-commerce is causing an exponential growth of RL. According to statistics, the forecast of the e-commerce sales in the USA and Canada are expected to reach $\$ 500$ billion by 2018 (Batarfi, Jaber \& Aljazzar, 2017). The world's largest e-commerce company (www.alibabagroup.com) sold through its platform about 9.3 billion dollars in 2014, resulted of 278 million purchase orders. However, the percentage of reverse flow was about $25 \%$ of their total operations, reaching even $40 \%$ for some products such as clothing (Pan, Chen \& Zhong, 2015), thus the e-commerce logistics has increased their attention on RL management (Qian, Han \& Da, 2011).

Reverse logistics can be a double-edged sword. It can be a source of savings or a source of additional expense reducing the effectiveness of the company instead of supporting it (Mimouni, Abouabdellah \& Abouabdellah, 2016). It is for this reason that there are many companies that work to formalize their RL processes, from the point of view of stablishing rules, procedures and communications, so that all stakeholders understand how to act in each moment (Huscroft, Hazen, Hall, Skipper \& Hanna, 2013).

In order to manage with greater guarantees the complexity of RL processes, it is fundamental to adapt traditional management (forward logistics processes) and know the great differences between these two types of logistics (Tibben-Lembke \& Rogers, 1995). This knowledge is necessary to achieve the maximum efficiency and profitability, as well as the complete control of the product life cycle. Thus, another fundamental aspect for the efficiency and profitability of RL processes is to facilitate decision making in these processes.

In the present work, based on a review of mathematical models of RL, the main decisions which need to be taken for RL processes will be identified, facilitating the achievement of the objectives based on costs, sustainability, customer service and so on. The identification of the main decisions of the RL process will allow the managers of this process to be able to know and understand them better, while offering an integrated vision of these processes and lastly, will lead to better results.

The remainder of this paper is organized as follows. In the second section, it exposes an introduction on the use of mathematic modeling in the field of RL. Subsequently, the main types of decisions that are taken in the field of RL are identified from the revised mathematical models. Finally, it includes the main conclusions obtained, as well as the future lines of research to be followed.

\section{The Mathematic Models Applied to the Reverse Logistics. A Systematic Literature Review}

\subsection{Literature Review Method}

The intention of the present work is analyze the mathematical models referring to the RL to identify the types of decision that are being worked in the field of RL. For this, the search for scientific material is focused on determinates keywords and related to each other, about the field of study.

With this intention, two types of keywords are defined, on the one hand those keywords that refer to "Reverse logistics" term and on the other hand those that are focused on "Mathematical Model", as can be appreciate in the following table:

As the central theme of this study is based on the identification of the main types of RL decisions from mathematical models, this research will focus on those works which the "decisions" term clearly emerges as key in the same.

It is proposed a period of analysis from those articles that are published since 2010, an interval between 7 and 8 years. Selecting the main databases of scientific works on the market (Scopus, Emerald, Sciencie Direct and IEEEXplore) a total of 91 potentially interesting papers are identified for the study object, by combining pairs of the previously showed keywords, in the content of Abstract, tittle or keywords. 


\begin{tabular}{|c|c|}
\hline Reverse Logistic & Mathematic Model \\
\hline Reverse logistic & Mathematic model \\
Reverse supply chain & Math programming models \\
Product recovery & Mathematic programming \\
Product return & \\
Closed-loop supply chain & \\
\hline
\end{tabular}

Table 1. Used keywords for literature review

After exhaustively analyzing all the articles identified, having discarded repeated and those papers whose subject matter was unrelated to the study, we have left a total of 41 articles directly related to the decision making of reverse logistics, through mathematical models.

\subsection{The mathematic Models in the Context of RL. A General Overview}

Reverse logistics processes help companies to fulfill their social responsibility and improve their reputation by offering a more respectful treatment for products and components. In general, companies create Reverse Supply Chain to comply with environmental regulations and reduce their operating cost by reusing products or components (Gu \& Liu, 2013).

Logistics managers have perceived that RL can be a market for efficiency gains and cost reductions, thus they have begun to pay more attention in this area, using it as a differentiating element of the market (Daugherty, Myers \& Richey, 2002).

Many large companies such as BWM, IBM, Kodak and Fuji Xerox, have established effective end-of-life product recovering and remanufacturing systems, in addition to their traditional production and distribution activities (Sun, Jian \& Zhang, 2015).

The results of the Sun et al., (2015) study show how increasing the rate of returned products causes an increase in the benefits of RL network members and the performance of the Closed-Loop Supply Chain (CLSC) system. For this reason, business organizations have realized the need to update their SC management, moving from a purely functional role to a strategic role, that allows them to comply with environmental regulations and provides them with a competitive advantage (Mutingi \& Mutingi, 2013).

Because the reverse logistics is more complex than forward or traditional logistics (Poole, 2003), the management of reverse flow information become essential for the correct management of the SC. In addition, due to the high uncertainty level in the RL management, managers take decisions to reduce it, trying to balance the rate of return with demand rates and better predict material recovery level (Asif, 2011). Therefore, it is vital to take a series of timely decisions that facilitate this improvement in results.

In traditional Supply Chain Management (SCM), quantitative models have been widely recognized as a powerful tool for decision support (Tayur, Ganeshan \& Magazine, 2012).

The modeling tools developed in the business environment are widely used because they offer a static representation of the system, although generally these tools offer an image of the company as an entity and not as an organization of the type business network (Mimouni et al., 2016).

Historically, quantitative models have contributed to improving decisions in two ways, directly and indirectly. On the one hand, they can be incorporated into software systems to automate and optimize decisions and, on the other hand, contribute to a better understanding of the interactions between the various processes, allowing these factors to be taken as determining information in the decisions (Dekker, Fleischmann \& Inderfurth, 2013).

For Reverse Supply Chain Management (RSCM) quantitative models are often applied and are practical, although most of the models used for RL are more conceptual (Brandenburg \& Seuring, 2014). The design of a RL modeling framework has always been a challenge, especially when there are different alternatives 
available, with some variability in the evaluation of these alternatives according to certain parameters (tangible and intangible), aggravated by a high quantity and quality uncertainty about product recovered (Gu \& Liu, 2013).

In this sense, a flexible and multi-criteria decision-making system that can choose the most suitable alternative according to a set of indicated criteria is required. Precisely, mathematical models are tools that, while respecting certain criteria and restrictions, allow decisions to be taken in favor of an optimal solution, making them a key tool for decision-making in the field of RL as well. For this reason, and considering that in the mathematical models used in the RL, relevant decision variables have been incorporated in each model, according to the decisions that were to be optimized, and then it is reviewed mathematical models used in the field of RL, from which the main types of modeled decisions can be inferred.

\section{Main Decisions of RL According to Mathematical Models}

Mathematical models have been widely used in the various domains of the RL. According to the reviewed literature, one of the domains that has been most investigated, through the development and application of mathematical models, has been the definition of the structure of the RL network.

An important issue in RL management systems is the question about RL channels should be integrated with those of Forward Logistics (FL) and how they should be dimensioned, from the point of view of identifying which actors will be shared at each site, what functions will be performed at each point and where and what relationship would exist between the FL and RL channels (Fleischmann, Bloemhof-Ruwaard, Dekker, van der Laan, van Nunen \& van Wassenhove, 1997). The selection and location of work centers, warehouses and partners are very common decisions in this type of studies.

In this sense, Prakash and Barua (2016) exposed a decision-making problem for the evaluation and prioritization of 3PL partners (third-party) selection criteria to outsource RL services. Also the work of Ravi, Shankar and Tiwari (2005) proposed a decision model on RL network structure and how to select RL partners, but in this case choosing between a Third Party Demanufacturing, Symbiotic Logistics Concept or Virtual Reverse Logistics Network.

In this same line, Jianghong (2010), proposes a programming model of the SC, where it tries to decide on the styles of collection and later treatment (collected by retailers, collected by external collectors or without recycling), taking into account all participants benefit not only the SC benefits.

In the work of Kizilboga, Mandil, Genevois and Zwolinski (2013), a model is shown that determines the optimal geographical locations and others determinant characteristics (quantity, capacity, services to be rendered and investment to be made) of remanufacturing centers, taking into account the economic and environmental impact.

In this same area but from another point of view, Krumwiede and Sheu (2002) proposed a decision-making model that aimed to guide third-party suppliers through the process of deciding whether to enter the RL market. Also, Ko and Evans (2007) designed an integrated FL and RL distribution network for a 3PL thirdparty service provider. In addition to make the decision on the external partners that will facilitate the management of the RL, Qian et al. (2011) used a mathematical model to determine the optimal number and location of factories and retailers in an e-commerce context, providing a broader view of the decision about the structure of the RL network. Within the e-commerce context, XiaoYan, Yong, Qinli and Stokes (2012), also propose a configuration model of the RL network based on the proportion of demand that is supplied and the market returns that are collected by each of components of the RL structure, with the firm intention of minimizing logistics costs.

In another relevant work, Dhib, Loukil, Addouche and Mhamedi (2013) proposed a mathematical model to select the best RL network (warehouses, reprocessing centers and recycling centers) under conditions of high uncertainty, taking into account sustainable indicators (economic, environmental and viability). Jayaraman, Patterson and Rolland (2003) offered a mathematical model to address the solution of strategic RL problems 
such as deciding whether each remanufacturing facility needs to be open or not, taking into account the return flow of products.

Also in this line, Ashfari, Sharifi, ElMekkawy and Peng (2014), El-Sayed, Afia and El-Kharbotly (2010), Ene and Öztürk (2014), Pedram, Yusoff, Udoncy, Mahat, Pedram and Babalola (2017), Harraz and Galal (2011), John, Sridharan and Kumar (2017) and Salema., Barbosa-Povoa and Novais (2007) proposed linear programming models to size and optimize the structure of the RL Network, marking the opening or not, location and size of facilities and service centers.

Demirel and Gökçen (2008) also addressed the problem of location of dismantling, collection and distribution facilities, but also provided optimum values of production and transportation of products to maximize the performance of the RL structure.

Entering into the strategic design of the RL network, Rezapour, Farahani, Fahimnia, Govindan and Mansouri (2015) presented a design model of a closed-loop RL network in where tried to determine not only the optimal number, capacity and location of the different RL management components, but also exposed a more tactical/operational planning in which it makes decisions on the policy of inventory management, transportation and storage, quantities of articles produced or transported between the different partners of the SC.

Following this last type of decision, Steeneck and Sarin (2013) emphasized two main currents through a revision of the literature regarding the tactical / operational decisions most common in the field of RL. On the one hand, they talked about production planning and control of refurbished products and, on the other hand they investigated the pricing of new and remanufactured products.

In the work of Han, Wu, Yang and Shang (2016), the impact of the price policy on consumer behavior was analyzed, but decisions were also taken on the types of production to be re-established and the quantities of each type to achieve the best results. In this area, Zhou, Xie, Gu, Lin and Ieromonachou (2016) and Zerhouni, Gayon and Frein (2013) showed models of forecasting of product returns, trying to facilitate decision-making with respect to the quantities to be manufactured, production and inventory levels, as well as the type of production most is convenient to realize. Other aspects such as the return policy and the quality of the product to be offered are also frequently treated in mathematical models applied to RL.

For example, the work of $\mathrm{Li}, \mathrm{Xu}$ and $\mathrm{Li}$ (2013), proposed a mathematical model that examines the impact of the decisions made by the company regarding the policy of returns, the quality of the product and the pricing strategy, with respect to the buying behavior and customer returns. The impact about consumer behavior on certain decisions regarding price policy and product quality was also studied through the analytical model of Ülkü and Hsuan (2017).

In the work of Yang, Hu, Zhao and Hu (2015), a CLSC is raised where costumer can obtain an economic refund when return the product. In this model, it seeks to optimize the benefits of all parties involved by setting the pricing policy for sales and refund products.

In this area, Desport, Liret, Lardeux, Di Cairano-Gilfedder, Lesaint and Owusu, (2016), Zerhouni et al. (2013), Zaarour, Melachrinoudis, Solomon and Min (2013) and Zhou et al. (2016) present forecasting models on product returns, trying to facilitate decisions making regarding the quantities to be manufactured, production levels and inventory, as well as the production type most convenient to realize.

Following this same line, Darbari, Agarwal, Chaudhary and Jha (2015), offer an implementation RL model with a triple development based on sustainability dimensions in a CLSC of computers, where they combine the manufacture of new products with the return and disassembly of recovered products, which also makes decisions regarding of the optimal number of products to disassemble and produce according to interest.

In the work of Jonrinaldi and Zhang (2010), we can see a model to coordinate the different cycles of inventory and production in a Reverse SC for multiple products in a finite horizon.

In relation to the type of production to be made, other interesting decisions that are also reflected in the literature, are directed towards the selection of components to configure recovered products. In this area, Kuik, Kaihara 
and Fujii (2016) showed a model that determines an optimal recovery plan for the manufacturer, deciding on the components when producing remanufactured items, from new, reused, rebuilt, or recycled. Kim, Song and Kim (2006) also focused on the decisions regarding the type of manufacturing, where several alternatives were discussed on the supply of parts (order new parts to external suppliers or use pieces of the returned products) to decide, in an optimal way, the quantity of pieces that will be processed of each type.

Also, Ramkumar, Subramanian, Narendran and Ganesh (2011), determine a model to minimize total costs about a CLSC of batteries, where they plan to take advantage of recycled lead or purchase a virgin lead for elaboration of new products, focusing on determining the type of component for each type of product.

A new parameter that serves as a central element in several studies is the determination of the logistic routes to be drawn. In this line, Erbao, Mingyong and Kai (2008), Achillas, Aidonis, Vlachokostas, Moussiopoulos, Banias and Triantafillou (2012) and Soysal (2016) offered three different models that aim to minimize logistical costs by deciding on routes to be drawn by the vehicles.

In the paper of Rahimi, Baboli and Rekik (2016), a model of inventory routes is proposed. In this model, the best route and the quantities of products that are delivered in each station, of perishable objects, are determined.

Another important and widely studied aspect in the literature regarding the type of decisions to be made, through the mathematical models applied to the RL, is the choice of the best treatment alternative to apply to the recovered products. On this subject, Saadany and Jaber (2010) presented a mathematical model that determines the viability of the post-treatment alternative for each recovered product, depending on the purchase price and the quality level of the product. Previously, Madaan, Wadhwa and Verma (2007) had offered a model for decision-making assistance on the alternative treatment of recovered products through a functional and logistic flow analysis. According to different criteria (economic, environmental, market, quality and legislation) Wadhwa, Madaan and Chan (2009) also determined the most suitable alternatives for each element recovered through a mathematical model. In addition, this model allows designing the return policy and planning the activities related to the RL in each alternative, in advance.

Another interesting study is that of Saadany and Jaber (2010), where they determine the viability or suitability of the post-treatment alternative for the recovered product, depending on the purchase price and the current quality level of the recovered product.

\section{Conclusions}

Mathematical models are considered as a powerful tool for decision making support, therefore have been widely used in research on RL. As indicated in the previous section, one of the main decisions on which these models are designed is the configuration and structure of the RL network.

In this sense, different decisions are made, from the selection of external partners, to the determination of the main characteristics of the network component centers. These decisions are based mainly on strategic measures, through which the company establishes its major objectives and determines the most effective way to achieve these objectives through correct decision-making.

The most relevant strategic decisions in supply chain management are based on plant location, modes of transport and location of distribution centers (Movahedipour, Yang, Zeng, Wu, Salam and Salam, 2016).

Although strategic planning could contain short-term determinants, it is common to cover medium or long-term goals. These decisions are taken with sufficient advance to be able to determine the planning of the operations and the future of the company in a horizon of generally between three and five years. The remaining decisions to be taken about the RL that have been detected in the analyzed literature: determination on the return policy, the quality of the product to be offered, the price strategy, production and inventory management, selection of components to configure recovered products, logistic routes and choice of the best treatment alternative are basically based on tactical/operational measures, which respond to the type of decisions focused on a short term. 
The following table shows the classification of the different types of decisions found. On the one hand the strategic decisions, with the configuration and structure of the network, and on the other hand, the tactical/operative decisions found un the literature of mathematical models applied to RL.

\begin{tabular}{|l|l|}
\hline \multicolumn{1}{|c|}{ Strategic decisions } & \multicolumn{1}{c|}{ Tactical / operational measures: } \\
\hline 1. Configuration and structure of the RL network & $\begin{array}{l}\text { 1. Return policy } \\
\text { 2. Quality of the product to be offered }\end{array}$ \\
& $\begin{array}{l}\text { 3. Price strategy } \\
\text { 4. Production and inventory management }\end{array}$ \\
& 5. Selection of components to configure recovered products \\
& 6. Logistics routes \\
& 7. Best treatment alternative \\
\hline
\end{tabular}

Table 2. Information about group of decision types

With the intention of identifying the different types of decisions related to RL, the present study has focused on the revision of mathematical models raised in the field of RL. A future line of work is to continue to review the literature to identify possible branches or secondary lines of each of the main lines identified, as well as to be able to explain in more detail the composition and elaboration of the revised mathematical models.

\section{Declaration of Conflicting Interests}

The authors declared no potential conflicts of interest with respect to the research, authorship, and/or publication of this article.

\section{Funding}

The authors received no financial support for the research, authorship, and/or publication of this article.

\section{References}

Achillas, C., Aidonis, D., Vlachokostas, C., Moussiopoulos, N., Banias, G., \& Triantafillou, D. (2012). A multi-objective decision-making model to select waste electrical and electronic equipment transportation media. Resources, Conservation and Recycling, 66, 76-84. https://doi.org/10.1016/j.resconrec.2012.01.004

Ashfari, H., Sharifi, M., ElMekkawy, T.Y., \& Peng, Q. (2014). Facility Location Decisions within Integrated Forward/Reverse Logistics under Uncertainty. Procedia CIRP, 17, 606-610.

https://doi.org/10.1016/j.procir.2014.01.092

Asif, R. (2011). Reverse Logistics: RFID the key to optimality. Journal of Industrial Engineering and Management, 4(2), 281-300.

Aziziankohan, A., Jolai, F., Khalilzadeh, M., Soltani, R., \& Tavakkoli-Moghaddam, R. (2017). Green supply chain management using the queuing theory to handle congestion and reduce energy consumption and emissions from supply chain transportation fleet. Journal of Industrial Engineering and Management, 10(2), 213. https://doi.org/10.3926/jiem.2170

Batarfi, R., Jaber, M.Y., \& Aljazzar, S.M. (2017). A profit maximization for a reverse logistics dual-channel supply chain with a return policy. Computers \& Industrial Engineering, 106, 58-82. https://doi.org/10.1016/j.cie.2017.01.024

Brandenburg, M., \& Seuring, S. (2014). Quantitative models for sustainable supply chain management: Developments and directions. European Journal of Operational Research, 233(2), 299-312.

https://doi.org/10.1016/j.ejor.2013.09.032

Darbari, J.D., Agarwal, V., Chaudhary, K., \& Jha, P.C. (2015). Multi-criteria decision approach for a sustainable reverse logistics network under fuzzy environment. In 2015 International Conference on Industrial Engineering and Operations Management (IEOM) (1-7). IEEE. https:/ / doi.org/10.1109/IEOM.2015.7093813 
Daugherty, P.J., Myers, M.B., \& Richey, R.G. (2002). Information Support for Reverse Logistics: The Influence of Relationship Commitment. Journal of Business Logistics, 23(1), 85-106.

https://doi.org/10.1002/j.2158-1592.2002.tb00017.x

Dekker, R., Fleischmann, M., \& Inderfurth, K. (2013). Reverse logistics: quantitative models for closed-loop supply chains. Available at: https://books.google.es/books?hl=es\&lr=\&id=nWL2BwAAQBAJ\&oi=fnd\&pg=PA3\&dq=Reverse+logistics: + quantitative + models + for + closed-loop + supply + chains\&ots $=$ WHBtfSblm5\&sig=4UB6r34ZWn-23UJDg2S8FfmGNAI

Demirel, N.Ö., \& Gökçen, H. (2008). A mixed integer programming model for remanufacturing in reverse logistics environment. The International Journal of Advanced Manufacturing Technology, 39(11-12), 1197-1206. https://doi.org/10.1007/s00170-007-1290-7

Desport, P., Liret, A., Lardeux, F., Di Cairano-Gilfedder, C., Lesaint, D., \& Owusu, G. (2016). Model and Combinatorial Optimization Methods for Tactical Planning in Closed-Loop Supply Chains.

https://doi.org/10.1109/ICTAI.2016.0137

Dhib, S., Loukil, T., Addouche, S.A., \& Mhamedi, A. El. (2013). Selecting configuration of reverse logistics network using sustainability indicators. Modeling, Simulation and Applied Optimization (ICMSAO), 2013 5th International Conference on, 1-5. https://doi.org/10.1109/ICMSAO.2013.6552567

El-Sayed, M., Afia, N., \& El-Kharbotly, A. (2010). A stochastic model for forward-reverse logistics network design under risk. Computers \& Industrial Engineering. Available at: http://www.sciencedirect.com/science/article/pii/S036083520800243X

Ene, S., \& Öztürk, N. (2014). Open Loop Reverse Supply Chain Network Design. Procedia - Social and Behavioral Sciences, 109, 1110-1115. https://doi.org/10.1016/j.sbspro.2013.12.596

Erbao, C., Mingyong, L., \& Kai, N. (2008). A Differential Evolution \&amp; Genetic Algorithm for Vehicle Routing Problem with Simultaneous Delivery and Pick-up and Time Windows. IFAC Proceedings Volumes, 41(2), 10576-10581. https://doi.org/10.3182/20080706-5-KR-1001.01791

Fleischmann, M., Bloemhof-Ruwaard, J.M., Dekker, R., van der Laan, E., van Nunen, J.A.E.E., \& van Wassenhove, L.N. (1997). Quantitative models for reverse logistics: A review. European Journal of Operational Research, 103(1), 1-17. https://doi.org/10.1016/S0377-2217(97)00230-0

Gu, Y., \& Liu, Q. (2013). Research on the application of the internet of things in reverse logistics information management. Journal of Industrial Engineering and Management, 6(4), 963-973.

Han, X., Wu, H., Yang, Q., \& Shang, J. (2016). Reverse channel selection under remanufacturing risks: Balancing profitability and robustness. International Journal of Production Economics, 182, 63-72.

https://doi.org/10.1016/j.ijpe.2016.08.013

Harraz, N.A., \& Galal, N.M. (2011). Design of Sustainable End-of-life Vehicle recovery network in Egypt. Ain Shams Engineering Journal, 2(3-4), 211-219. https://doi.org/10.1016/j.asej.2011.09.006

Huscroft, J.R., Hazen, B.T., Hall, D.J., Skipper, J.B., \& Hanna, J.B. (2013). Reverse logistics: past research, current management issues, and future directions. The International Journal of Logistics Management, 24(3), 304-327. https://doi.org/10.1108/IJLM-04-2012-0024

Jayaraman, V., Patterson, R., \& Rolland, E. (2003). The design of reverse distribution networks: models and solution procedures. European Journal of Operational. Retrieved from http://www.sciencedirect.com/science/article/pii/S0377221702004976

Jianghong, M. (2010). Research on the Collection Policy of Integrated Supply Chain Based on Remanufacture. In 2010 International Conference on Intelligent Computation Technology and Automation (144-147). IEEE. https://doi.org/10.1109/ICICTA.2010.520

John, S.T., Sridharan, R., \& Kumar, P.N.R. (2017). Multi-period reverse logistics network design with emission cost. The International Journal of Logistics Management, 28(1), 127-149. https://doi.org/10.1108/IJLM-08-2015-0143 
Jonrinaldi, \& Zhang, D.Z. (2010). Optimal integrated production and inventory cycles in a whole green manufacturing supply chain network with coordination. In The 40th International Conference on Computers \& Indutrial Engineering (1-6). IEEE. https://doi.org/10.1109/ICCIE.2010.5668191

Kim, K., Song, I., \& Kim, J. (2006). Supply planning model for remanufacturing system in reverse logistics environment. Computers \& Industrial Engineering, 51(2), 279-287. https://doi.org/10.1016/j.cie.2006.02.008

Kizilboga, G., Mandil, G., Genevois, M.E., \& Zwolinski, P. (2013). Remanufacturing Network Design Modeling: A Case of Diesel Particulate Filter. Procedia CIRP, 11, 163-168. https://doi.org/10.1016/j.procir.2013.07.048

Ko, H.J., \& Evans, G.W. (2007). A genetic algorithm-based heuristic for the dynamic integrated forward/reverse logistics network for 3PLs. Computers \& Operations Research, 34(2), 346-366. https://doi.org/10.1016/j.cor.2005.03.004

Krumwiede, D.W., \& Sheu, C. (2002). A model for reverse logistics entry by third-party providers. Omega, 30(5), 325-333. https://doi.org/10.1016/S0305-0483(02)00049-X

Kuik, S., Kaihara, T., \& Fujii, N. (2016). Product Recovery Configuration Decisions for Achieving Sustainable Manufacturing. Procedia CIRP. Available at: http://www.sciencedirect.com/science/article/pii/S2212827116002109

Li, Y., Xu, L., \& Li, D. (2013). Examining relationships between the return policy, product quality, and pricing strategy in online direct selling. International Journal of Production Economics, 144(2), 451-460. https://doi.org/10.1016/j.ijpe.2013.03.013

Madaan, J., Wadhwa, S., \& Verma, M. (2007). Integrated framework for reverse logistics system: Improved decision making prospective. IFAC Proceedings Volumes. Available at: http://www.sciencedirect.com/science/article/pii/S1474667015322394

Mimouni, F., Abouabdellah, A., \& Abouabdellah, A. (2016). Proposition of a modeling and an analysis methodology of integrated reverse logistics chain in the direct chain. Journal of Industrial Engineering and Management, 9(2), 359. https://doi.org/10.3926/jiem.1720

Movahedipour, M., Yang, M., Zeng, J., Wu, X., Salam, S., \& Salam, S. (2016). Optimization in supply chain management, the current state and future directions: A systematic review and bibliometric analysis. Journal of Industrial Engineering and Management, 9(4), 933. https://doi.org/10.3926/jiem.2035

Mutingi, M., \& Mutingi, M. (2013). Developing green supply chain management strategies: A taxonomic approach. Journal of Industrial Engineering and Management, 6(2), 525-546. https://doi.org/10.3926/jiem.475

Pan, S., Chen, C., \& Zhong, R.Y. (2015). A crowdsourcing solution to collect e-commerce reverse flows in metropolitan areas. IFAC-PapersOnLine, 48(3), 1984-1989. https://doi.org/10.1016/j.ifacol.2015.06.379

Pedram, A., Yusoff, N.B., Udoncy, O.E., Mahat, A.B., Pedram, P., \& Babalola, A. (2017). Integrated forward and reverse supply chain: A tire case study. Waste Management, 60, 460-470. https://doi.org/10.1016/j.wasman.2016.06.029

Pokharel, S., \& Mutha, A. (2009). Perspectives in reverse logistics: A review. Resources, Conservation and Recycling, 53(4), 175-182. https://doi.org/10.1016/j.resconrec.2008.11.006

Poole, K. (2003). Seizing the potential of the service supply chain. Supply Chain Management Review, 7(4). Available at: https://trid.trb.org/view.aspx?id $=606663$

Prakash, C., \& Barua, M.K. (2016). A combined MCDM approach for evaluation and selection of third-party reverse logistics partner for Indian electronics industry. Sustainable Production and Consumption, 7, 66-78. https://doi.org/10.1016/j.spc.2016.04.001

Qian, X., Han, Y., \& Da, Q. (2011). Reverse logistics network design model based on e-commence. Artificial Intelligence, Management. Available at: http://ieeexplore.ieee.org/abstract/document/6010526/

Rahimi, M., Baboli, A., \& Rekik, Y. (2016). Sustainable Inventory Routing Problem for Perishable Products by Considering Reverse Logistic. IFAC-PapersOnLine, 49(12), 949-954. https://doi.org/10.1016/j.ifacol.2016.07.898 
Ramkumar, N., Subramanian, P., Narendran, T.T., \& Ganesh, K. (2011). Erratum to "A genetic algorithm approach for solving a closed loop supply chain model: A case of battery recycling" [Appl. Math. Modell. 34 (2010) 655670]. Applied Mathematical Modelling, (35)12, 5921-5932. https://doi.org/10.1016/j.apm.2011.05.026

Ravi, V., Shankar, R., \& Tiwari, M.K. (2005). Analyzing alternatives in reverse logistics for end-of-life computers: ANP and balanced scorecard approach. Computers \& Industrial Engineering, 48(2), 327-356. https://doi.org/10.1016/j.cie.2005.01.017

Rezapour, S., Farahani, R.Z., Fahimnia, B., Govindan, K., \& Mansouri, Y. (2015). Competitive closed-loop supply chain network design with price-dependent demands. Journal of Cleaner Production, 93, $251-272$. https://doi.org/10.1016/j.jclepro.2014.12.095

Saadany, A. El, \& Jaber, M. (2010). A production/remanufacturing inventory model with price and quality dependant return rate. Computers \& Industrial Engineering. Available at: http://www.sciencedirect.com/science/article/pii/S0360835209000369

Salema, M.I.G., Barbosa-Povoa, A.P., \& Novais, A.Q. (2007). An optimization model for the design of a capacitated multi-product reverse logistics network with uncertainty. European Journal of Operational Research, 179(3), 1063-1077. https://doi.org/10.1016/j.ejor.2005.05.032

Soysal, M. (2016). Closed-loop Inventory Routing Problem for returnable transport items. Transportation Research Part D: Transport and Environment, 48, 31-45. https://doi.org/10.1016/j.trd.2016.07.001

Steeneck, D., \& Sarin, S. (2013). Pricing and production planning for reverse supply chain: a review. International Journal of Production. Available at: http://www.tandfonline.com/doi/abs/10.1080/00207543.2013.836780

Sun, H., Jian, L., \& Zhang, G. (2015). Research on closed-loop supply chain network equilibrium with two-type suppliers, risk-averse manufacturers and capacity constraints. Journal of Industrial Engineering and Management, 8(2), 509-529. https://doi.org/10.3926/jiem.1336

Tayur, S., Ganeshan, R., \& Magazine, M. (2012). Quantitative models for supply chain management. Available at: https://books.google.es/books?

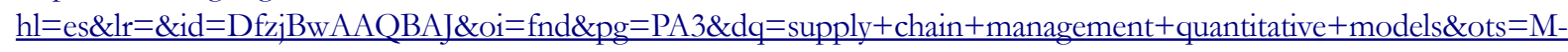
$\underline{\text { mo13YrR1\&sig=BJRrxVXyYf8w9QcGfYdnDHtzgkE }}$

Tibben-Lembke, R.S., \& Rogers, D.S. (1995). Supply Chain Management: An International Journal Differences between forward and reverse logistics in a retail environment. An International Journal Iss International Journal of Physical Distribution \&amp Logistics Management International Journal of Physical Distribution \&amp Logistics Management, 7(2), 271-282. Retrieved from http://dx.doi.org/10.1108/13598540210447719

Ülkü, M.A., \& Hsuan, J. (2017). Towards sustainable consumption and production: Competitive pricing of modular products for green consumers. Journal of Cleaner Production, 142, 4230-4242.

https://doi.org/10.1016/j.jclepro.2016.11.050

Wadhwa, S., Madaan, J., \& Chan, F. (2009). Flexible decision modeling of reverse logistics system: A value adding MCDM approach for alternative selection. Robotics and Computer-Integrated. Available at: http://www.sciencedirect.com/science/article/pii/S0736584508000112

Xiao Yan Q., Yong, H., Qinli, D., \& Stokes, P. (2012). Reverse logistics network design model based on e-commerce. International Journal of Organizational Analysis, 20(2), 251-261.

https://doi.org/10.1108/19348831211227864

Yang, F., Hu, P., Zhao, F., \& Hu, C. (2015). Customer returns model in a dual-channel supply chain. Journal of Modelling in Management, 10(3), 360-379. https://doi.org/10.1108/JM2-03-2015-0014

Zaarour, N., Melachrinoudis, E., Solomon, M.M., \& Min, H. (2013). Optimal Collection Period for Returned Products in the Reverse Supply Chain. IFAC Proceedings Volumes, 46(9), 123-127. https://doi.org/10.3182/20130619-3-RU3018.00234 
Zerhouni, H., Gayon, J., \& Frein, Y. (2013). Influence of dependency between demands and returns in a reverse logistics system. International Journal of Production. Available at: http://www.sciencedirect.com/science/article/pii/S092552731000407X

Zhou, L., Xie, J., Gu, X., Lin, Y., \& Ieromonachou, P. (2016). Forecasting return of used products for remanufacturing using Graphical Evaluation and Review Technique (GERT). International Journal of. Available at: http://www.sciencedirect.com/science/article/pii/S0925527316300421

Journal of Industrial Engineering and Management, 2018 (www.jiem.org)

\section{(c) (1) $(9$}

Article's contents are provided on an Attribution-Non Commercial 4.0 Creative commons International License. Readers are allowed to copy, distribute and communicate article's contents, provided the author's and Journal of Industrial Engineering and Management's names are included. It must not be used for commercial purposes. To see the complete license contents, please visit https://creativecommons.org/licenses/by-nc/4.0/. 